\title{
Thermal comfort in operating rooms: a case study
}

\author{
F. Patania ${ }^{1}$, A. Gagliano ${ }^{1}$, F. Nocera ${ }^{1,2}$ \& A. Galesi ${ }^{1}$ \\ ${ }^{I}$ Energy and Environment Division of D.I.I.M., \\ Engineering Faculty of University of Catania, Italy \\ ${ }^{2}$ Faculty of Architecture of University of Catania, Italy
}

\begin{abstract}
This paper focuses on thermal comfort in hospital operating rooms (ORs).

Thermal comfort depends on several factors such as temperature conditions of the operating room, insulation of protective clothing, stress, rate of metabolism and safety mechanisms in the body to keep core temperature stable. The modification of any of these elements triggers defense mechanisms which in extreme cases may lead to serious disturbances in the body. The maintenance of recommended standards (ISO 7330) concerning thermal conditions in operating rooms ensures the highest possible physical capabilities of the personnel while providing maximum safety for the patients. The purpose of the present work is to report the results obtained during an experimental campaign carried out at the Umberto I Hospital in Enna in order to improve efficiency of HVAC installations to secure thermal comfort in the operating rooms.
\end{abstract}

Keywords: operating rooms, thermal stress, thermal comfort.

\section{Introduction}

A person produces thermal energy through the oxidation of glucose from what they have consumed. This process is named metabolism. A great part of this energy $(80 \%)$ is used for the maintenance of the body, while $20 \%$ is expended in work. Oxidation can increase in some situations, for example, with increased activity level or increased body temperature. Indoors, the temperature of the human body remains constant. The normal temperature is about $37^{\circ} \mathrm{C}$. Outside these limits, a person is considered to be sick. However, they can survive at a minimum temperature of $32^{\circ} \mathrm{C}$ and at a maximum of $42^{\circ} \mathrm{C}$ [1]. Heat transfers 
between the person and the environment. The body uses thermo-regulatory mechanisms to compensate the gain or loss of heat to keep body temperature in equilibrium. This system is known as the hypothalamic thermostat, which "tells" the body to increase or decrease the temperature, in accordance with thermal needs. A person is in thermal comfort when he/she is satisfied with the thermal environment $[2,3]$ and does not need to use their thermo-regulator mechanism. Factors which affect the thermal comfort include physiological perception, climate, the level and type of physical activity, and the types of clothes used. Thermal comfort in relation to environmental factors depends on environment temperature, radiant temperature, relative humidity, air velocity, level and type of activity, metabolic rates, and clothing [2]. Hospital operating rooms (ORs) require efficient HVAC installations to secure the highly demanding indoor environmental conditions for patients and medical personnel.

Understanding and managing the thermal comfort in Operating Rooms (ORs) is complex because each surgery can present different levels and types of activities of the staff, different patient requirements and so on. Figure 1 shows a typical configuration of one OR. The "thermal risks" of the patient is more difficult to resolve, because the patient is anesthetized and, therefore, his/her thermo-regulatory mechanisms are not in action and an inadequate environment temperature could cause hypothermia. A temperature between $24^{\circ} \mathrm{C}$ and $26^{\circ} \mathrm{C}$ is suitable, while temperatures below $21^{\circ} \mathrm{C}$ put the patient at risk of becoming hypothermic [4]. Consequently, it is an extremely interesting study and analyzes the ORs in order to ensure the recommended standards concerning thermal conditions and so to guarantee the highest possible physical capabilities of the personnel while providing maximum safety for the patients. The purpose of this paper is to evaluate the thermal comfort in the Enna Hospital Operating Rooms, considering all parameters necessary to verify the respect of the recommended standards of ISO EN 7730, 2005 and CR 1752, 1998.

\section{Investigation methodology}

The authors carried out a monitoring analysis, during the period from 1 July 2008 to 6 August 2008, of the thermal comfort in the Operating rooms at the Hospital "Umberto I" in Enna. The research was developed in two contemporaneous steps: an "objective investigation" and a "subjective" one.

The "objective investigation" pointed at calculating the thermal comfort Fanger's indices: Predicted Mean Vote (PMV), Predicted Percentage dissatisfied (PPD) and Draft Risk (DR), by means of the measured value of the air temperature, mean radiant temperature, air relative humidity, air velocity and water vapor pressure.

The "subjective investigation" was carried out giving a questionnaire to the staff members (two surgeons, two assistants and two nurses) to determine their sensations of comfort or discomfort felt in the operating room. 


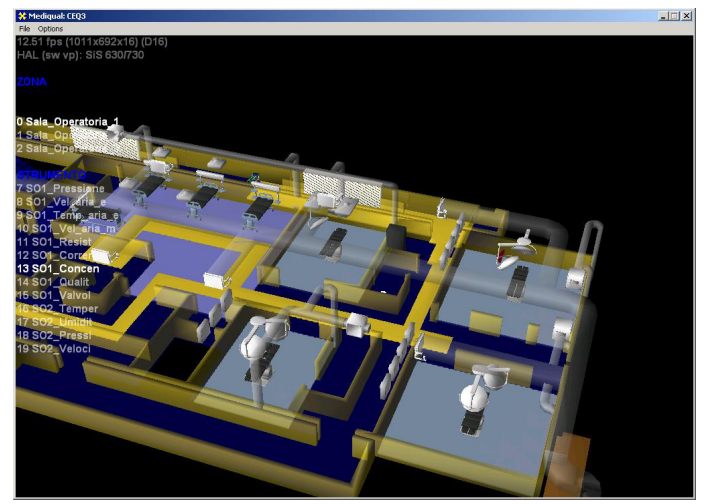

Figure 1: $\quad 3 \mathrm{D}$ view of the monitored operating rooms.

\subsection{The "objective investigation"}

The thermal environment was analyzed by means of field measurement campaigns. The CEQ (Controlled Environment Qualification) system of Keita srl was used to perform the measurements of air temperature, mean radiant temperature, air relative humidity, air velocity, water vapor pressure, flow rate of supply and return air, and so on. The CEQ system has a network of transducers that transmit their signals to a central computer which acquires the signals and converts them into data, charts and reports alarms. The three operating rooms were monitored continuously and simultaneously all the year around. The recorded data processed in the period from 1 July 2008 to 6 August 2008 were elaborated in order to evaluate the thermal comfort Fanger's indices, PMV, PPD and DR according to the International Standard ISO 7730 [5]. The Predicted Mean Vote (PMV) is the mean vote expected to arise from averaging the thermal sensation vote of a large group of people in a given environment. PMV is derived from the physics of heat transfer combined with an empirical fit to sensation. PMV establishes a thermal strain based on steady-state heat transfer between the body and the environment and assigns a comfort vote to that amount of strain. The PMV is a complex mathematical expression involving activity, clothing and the four environmental parameters. It is expressed by equation:

$$
\mathrm{PMV}=\left(0,303 \mathrm{xe}^{-0,036 \mathrm{M}}+0,028\right) \mathrm{L}
$$

in which $\mathrm{M}$ is metabolic rate $\left(\mathrm{W} / \mathrm{m}^{2}\right)$ and $\mathrm{L}(\mathrm{W})$ is thermal load defined as the difference between the internal heat production and the heat loss to the actual environment for a person hypothetically kept at comfort values of skin temperature and evaporative heat loss by sweating at the actual activity level. The term Predicted Percentage Dissatisfied (PPD) is a quantitative measure of the thermal comfort of a group of people at a particular thermal environment. The PPD is related to the PMV as follows:

$$
\mathrm{PPD}=100-95 \mathrm{e}^{-\left(0,03353 \mathrm{PMV}^{4}+0,2179 \mathrm{PMV}^{2}\right)}
$$


The term Draft Risk (DR) is the predicted of people dissatisfied due to unwanted local cooling of the body caused by air movement and it is expressed by the following equation:

$$
\mathrm{DR}=\left(34-\mathrm{t}_{\mathrm{a}}\right)\left(\mathrm{V}_{\mathrm{a}}-0,05\right)^{0,62}\left(0,37 \mathrm{~V}_{\mathrm{a}} \mathrm{T}_{\mathrm{U}}+3,14\right)
$$

where $t_{a}$ is the air temperature, $V_{a}$ is the air velocity and $T_{u}$ is the turbulence intensity. In the evaluation of such indices the metabolic rate was fixed at 1.4 met while the actual people's clothing came from the questionnaires.

\subsection{The "subjective investigation"}

A subjective investigation has been carried out to determine the wellbeing or discomfort sensations of the operating staff. Each surgical staff member was given a questionnaire concerned their physical characteristics (age, sex, weight, etc...), the job and the clothing they wore and the subject's judgment on the thermal environment, the overall comfort sensations and requests of eventual changes of the microclimatic characteristics of the operating room. The questionnaire was divided in three sections concerning: general information; thermal comfort; air quality. The questions in the section of thermal comfort concerned how the thermal environment was felt. In particular, surgical staff members gave a judgment about its acceptability and preference, answering the following questions:

1) "How do you consider the thermal environment in the operation room?"

2) "Would you prefer to feel warmer, cooler or no change?"

3) "Do you feel unpleasant air currents on some areas of your body?"

The judgments about the thermal environment have been compared with the results of the field measurements. Moreover, the subjective mean votes have been compared with the thermal environment perceptions in terms of acceptability and preference.

\section{Results analysis}

The thermal environment was analyzed by means the CEQ (Controlled Environment Qualification) system of Keita srl to measure air temperature, mean radiant temperature, air relative humidity, air velocity, water vapor pressure, flow rate of supply and return air, and so on.

During the monitored period the Air changes was always more or less $20 \mathrm{Vol} / \mathrm{h}$

The analysis of this graph shows that the OR temperature is always between the values of $21^{\circ} \mathrm{C}$ and $23^{\circ} \mathrm{C}$ and only for a few days the temperature goes below the value of $21^{\circ} \mathrm{C}$.

This condition could put the patient at risk of becoming hypothermic [6], so it is necessary to increase the air supply temperature considering that in operating 


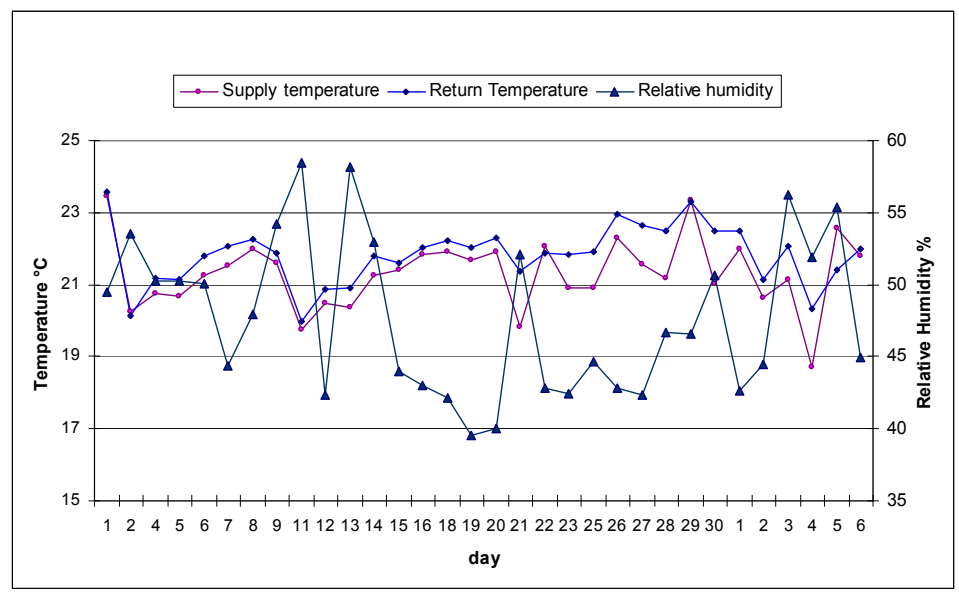

Figure 2: $\quad$ Variation of the air temperature and the $\mathrm{RH}$ in the OR.

rooms the thermal environment for the patient is prioritized over the staff. However, a temperature of $>23^{\circ} \mathrm{C}$ is usually intolerable for the surgical staff $[6,7]$.

For each day of investigation the hourly value of thermal Fanger indexes have been calculated. The measured data indicate that all the parameters vary during the duty period, so for each day of monitoring the minimum and the maximum value for each parameter have been pointed out.

The acceptable PMV range for these typologies of environment has been fixed between -0.2 (slightly cool sensation) and +0.2 (slightly warm sensation) [8]. Figure 3 shows the variation for PMV index during the whole period of monitoring. Overall, it was noticed a similar trend of all the indices calculated for all three operating rooms.

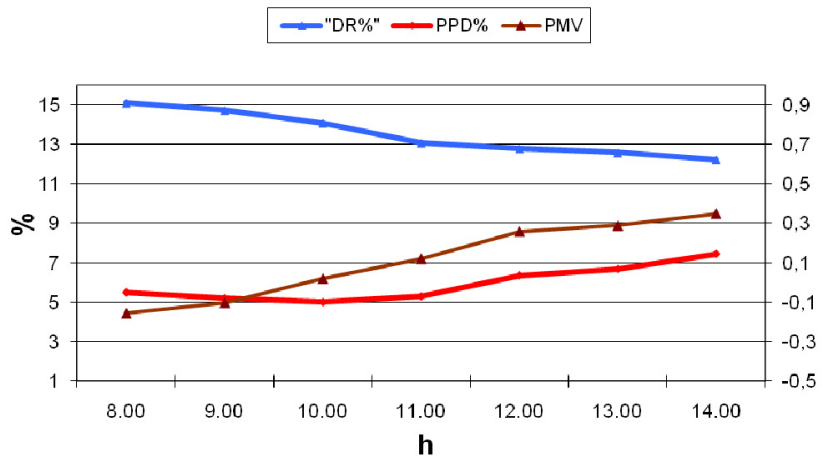

Figure 3: Daily variation of PMV, PPD and DR during a monitored day. 


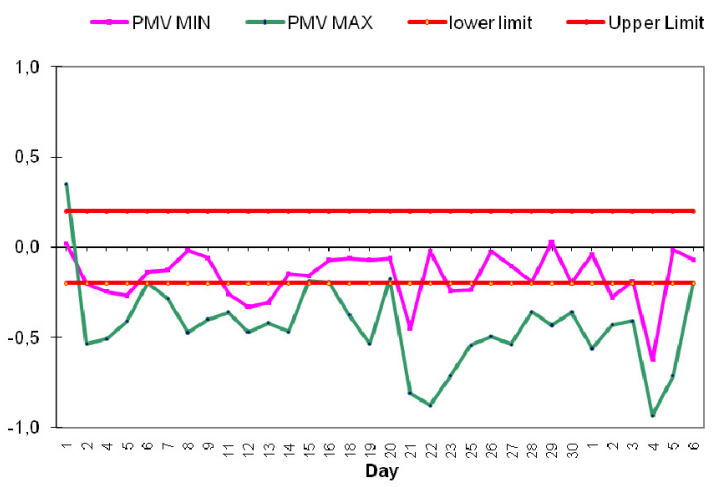

Figure 4: $\quad$ Trend of PMV index and law limit in OR n.1.

As shown in Figure 3, the minimum daily value of PMV remained substantially in the range of \pm 0.2 except for some days, while the maximum daily value of PMV is always less than -0.2 and does not exceed the value of $-0,5$ except for some critical days (see Table 1 ).

Globally, these results indicate that the member of staff would felt "slightly cool" or cool. By means equation (2) the correlated PPD values have been calculated. Therefore for a value of $\mathrm{PMV}_{\mathrm{s}}$ of \pm 0.2 the correlated PPD result of $6 \%$, while for a $\mathrm{PMV}_{\mathrm{s}}$ of -0.5 result of $10 \%$. This "objective analysis" has been compared with the questionnaire responses. Figures 5 and 6 show the summary of the responses to the questions $\mathrm{nn}$. 1) and 2). It is possible to notice that the responses to the two questions are in perfect agreement. In fact $27 \%$ of persons are in neutral conditions (D1 and B1), 33\% or 39\% of person felts slight discomfort (E1 and B2), $27 \%$ or $22 \%$ of persons felt discomfort (F1+B1 and $\mathrm{C} 2) ; 11 \%$ of persons felt high discomfort (A1+G1 and D2). With reference to the PPD the value of $10 \%$ calculated by Fanger theory more or less is in accordance with the $11 \%$ of person feeling high discomfort (A1+G1 and D2). We can also

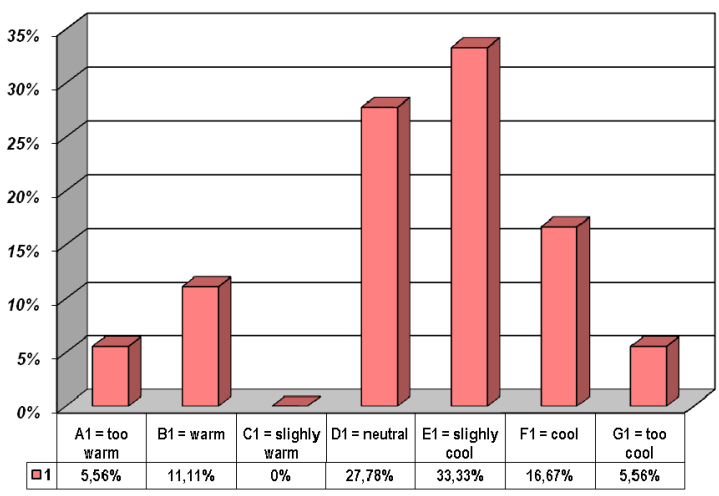

Figure 5: Responses to the Qs n.1. 


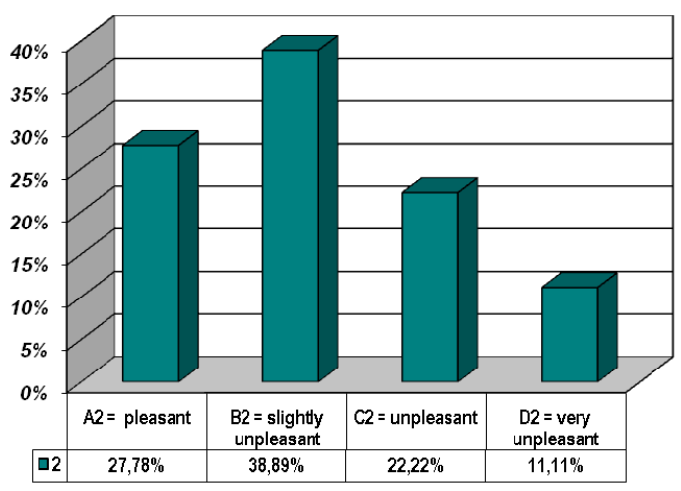

Figure 6: Responses to the Qs n.2.

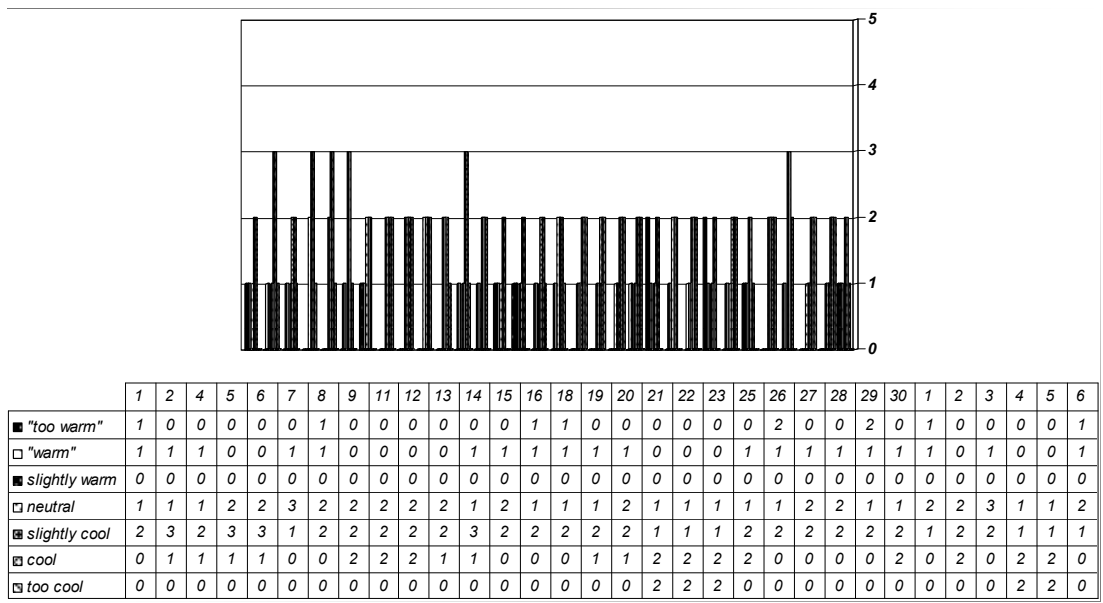

Figure 7: Typologies of responses of each member of the staff.

observe that globally the $55,5 \%$ of the responses indicate a thermal sensation of slightly cool or cool, the $28 \%$ indicate a thermal sensation of neutrality and the $16,5 \%$ indicate slightly warm or warm. The $16,5 \%$ of responses that indicate slightly warm or warm appear in contrast with the calculated values of PMV that do not indicate these typologies of sensations.

The reason of these discrepancies could be found out by observing the responses of each member of the staff as shown in figure 7 . It is possible to observe that each member of the staff gives a different answer in respect of his thermal sensation. These variabilities could depend on the different levels and types of activities of the staff and by the clothes worn by the person in the OR that are different in function of the activities of each member of the staff. It usually happens that the thermal sensation of the surgeon is warm, while the anaesthesiologist and nurse feel the thermal sensation of cool. Table 1 summarizes the more critical thermal conditions registered during the campaign 
of survey. For these days, characterised by PMV of less than -0.5 , it is possible to notice the good correlation between the values of Fanger indexes and the answer of the member staff, in fact almost all the people feel a thermal sensation of cool. These results indicate that it is impossible to specify a thermal environment that will satisfy everybody. There will always be a percentage of occupants who perceive thermal discomfort.

Table 1: $\quad$ Critical values of PMV and PPD

\begin{tabular}{|c|c|c|c|}
\hline Date & OR & PMV max & PPD max \\
\hline 21 July & 1 & $-0,81$ & 16.46 \\
\hline 22 July & 1 & $-0,88$ & 18.12 \\
\hline 23 July & 1 & $-0,71$ & 14.15 \\
\hline 4 August & 1 & $-0,93$ & 19.32 \\
\hline 5August & 1 & $-0,71$ & 14.15 \\
\hline
\end{tabular}

Moreover, as shown in figure 8, the minimum value of DR assumed a value of $15 \%$ in all three OR while the daily maximum value was always higher than the value of $15 \%$.

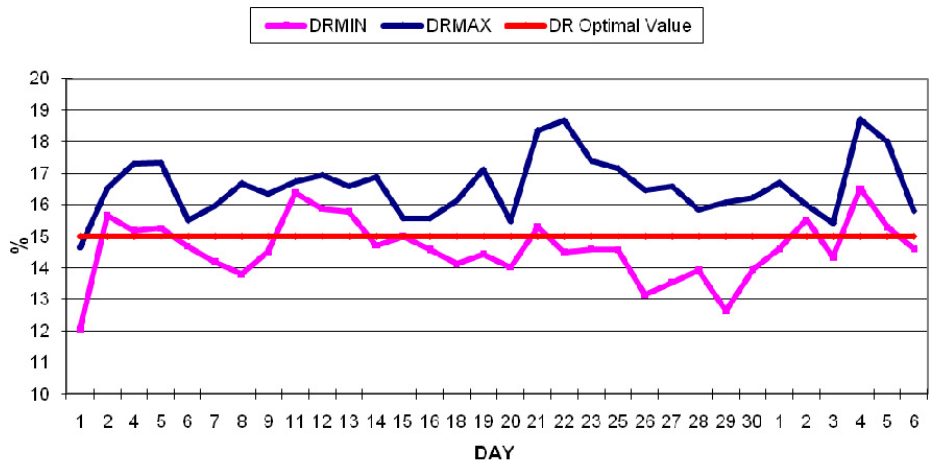

Figure 8: $\quad$ Trend of DR index and optimal value in OR n.1.

These values, according the UNI EN ISO 7730, indicate a situation of discomfort due to air current (draft), as confirmed in the questionnaire responses: all the members of staff perceived air currents on the neck and the head as predicted by the DR index.

These results indicate the necessity to properly locate the supply outlets and extraction ports in optimal locations to reduce the air currents. The recommended ventilation system has to deliver air from the ceiling in a downward movement to several exhaust inlets located on opposite walls and barriers dividing the ceiling of the diffuser. Anyway, globally the environment has been considered "acceptable" for more than $70 \%$ of the occupants and the main complaints concern: low temperature, presence of annoying cold. $11 \%$ of the occupants have defined the environmental condition "comfortable" while $16 \%$ of the occupants have defined the environmental condition "poorly tolerable". 


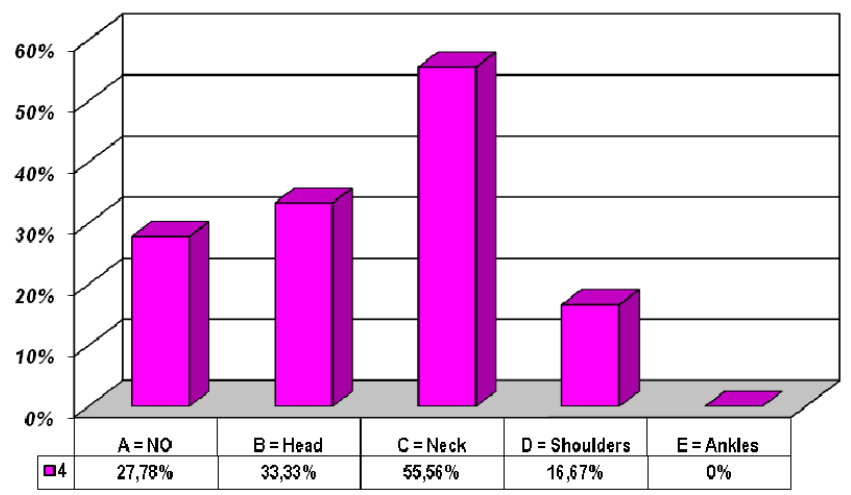

Figure 9: Responses to the Qs n. 3.

\section{Conclusions}

In this paper an in-field investigation methodology on thermal comfort was applied.

The environmental parameters influencing thermal comfort were measured while, at the same time, the subjective judgments of the people about the thermal environment were expressed and significant tendency and correlation were found out.

The developed investigations highlighted the key findings as follow:

- the calculated Fanger indexes are in agreement with the subjective judgments of the people

- the acceptable range of PMV for the OR have to maintain in the range of $\pm 0.2$

- the member of the staff reported different thermal sensation during surgery in relation to their function; often the thermal sensation of the surgeon and nurse is hot, while the anaesthesiologist sometimes feels the thermal sensation of cold

- the DR is the index that indicate the more negative judgments

So it is really important to concentrate the effort in two directions:

1) optimize the thermal comfort for the Staff, and at the same time ensure an adequate environment temperature for the patient, while preventing hypothermia, maintaining the ambient temperature in the range of $22-$ $23^{\circ} \mathrm{C}$

2) reduce the air currents on the neck and the head adopting air supply system that minimize harmful effects like short-circuit among air supply and air expulsions, the local undercooling caused by a too high residual speed of the air supply. 


\section{References}

[1] A. C. Guyton, 1988. "Fisiologia Humana", Guanabara Koogan, Rio de Janeiro.

[2] American Society of Heating Refrigerating and Air-conditioning Engineers (ASHRAE), 2004. "Thermal Environment Conditions for Human Occupancy". Atlanta.

[3] Nederlands Normalisatie-instituut (NEN-ENISO 7730, 2005. "Ergonomics of the thermal environment - Analytical determination and interpretation of thermal comfort using calculation of PMV and PPD indices and local thermal comfort". Delft

[4] Johnston, I.D.A and Hunter, A. R., 1984. 'The design and utilization of operating theatres'. The Royal College of Surgeons of England.

[5] ISO. Moderate thermal environments - determination of the PMV and PPD indices and specification of the conditions for thermal comfort. ISO 7730. Geneve: International Organization for Standardization;1998

[6] Leslie, K. and Sessler, D.I., 2003. "Perioperative Hypothermia in the highrisk surgical patient". Best Practice \& Research Clinical Anaesthesiology. Vol.17, n4, pp. 485-498

[7] Wildt, M., 1996. "Pressure Hierarchy and Indoor Climate of Hospital Rooms". M. Maroni (ed.). Ventilation and Indoor Air Quality in Hospitals, 219-225. Kluwer Academic Publishers.

[8] Ilona Frohner and László Bánhidi - Comfort Ranges Drawn up Based on the PMV Equation as a Tool for Evaluating Thermal Sensation Proceedings of Clima 2007 WellBeing Indoors 